\title{
The pelvic ring of pain: Pregnant women's experiences of severe pelvic girdle pain: An interview study
}

\author{
Helen Elden ${ }^{1}$, I ngela Lundgren ${ }^{1}$, Eva Robertson ${ }^{2}$ \\ 1. Institute of Health and Care Sciences, The Sahlgrenska Academy at University of Gothenburg, Sweden. 2. Faculty of \\ Professional studies, University of Nordland, Bodø, Norway.
}

Correspondence: Helen Elden. Address: Institute of Health and Care Sciences, The Sahlgrenska Academy at University of Gothenburg Box 457, 40530 Gothenburg, Sweden. Email: Helen.elden@gu.se

Received: November 28, 2013

Accepted: February 6, 2014

Online Published: February 13, 2014

DOI : $10.5430 /$ cns.v2n2p30

URL: http://dx.doi.org/10.5430/cns.v2n2p30

\section{Abstract}

Background: Pelvic girdle pain (PGP) is a universal problem affecting approximately 50\% of all pregnant women. For 25 to $30 \%$ of pregnant women the problem becomes severe.

Methods: In-depth interviews were carried out with 27 pregnant women with severe PGP in 2009-2010. Qualitative content analysis was used.

Results: The women's experiences are summarized in four categories: A strange body; the body on guard; relation and support from health care and, acceptance of PGP.

Conclusions: PGP completely preoccupied women with severe PGP. It influenced their self-evident trust in their bodies as well as their capabilities to guide and control them. The fear of triggering pain and unpleasant sensations made them avoid movement. They experienced anxiety and worry of not being able to manage their pregnancy and childbirth, and bind to their unborn child. They felt worse that their complaints are trivialized, and not taken seriously in health care. To be able to cope with PGP, they had to accept it and realize that they have to be aware and accept their bodies' limitations. This means working with their bodies and not against them. PGP made the women look upon life more seriously and changed their self-perception. Increased awareness and knowledge are needed among healthcare to enable them to meet these women's needs and provide them with adequate support. Information about PGP could be sent home with the woman at the first visit to the midwife. This would probably prevent or reduce the worry that can arise in women suffering severe PGP.

\section{Key words}

Experience, Pregnancy, Pelvic girdle pain, Qualitative interview study

\section{Introduction}

Pelvic girdle pain (PGP) is a universal problem affecting approximately $50 \%$ of all pregnant women ${ }^{[1,2]}$ regardless of socioeconomic factors ${ }^{[3-7]}$. It is a musculoskeletal pain located within the pelvic area between the posterior iliac crest and gluteal folds, with or without leg pain ${ }^{[8]}$. Prevalence estimates for PGP range widely from $20 \%$ overall ${ }^{[8]} 35-50 \%$ in early 
pregnancy and $60 \%-70 \%$ in late pregnancy ${ }^{[9,10]}$. For 25 to $30 \%$ of pregnant women the problem becomes severe ${ }^{[1,2,11]}$. The majority of women recover from PGP the first few months after delivery whether they have received treatment or not ${ }^{[12]}$. However, PGP from the postpartum stage to 3 years after childbirth has a reported prevalence of $9 \%$ to $20 \%$ and $6 \%$ of women have persistent pain 6 years after ${ }^{[13,14]}$. The reason for the discrepant results reflects that some studies are prospective and some are retrospective and that different diagnostic tools and criteria have been used. In addition, the diagnosis in most of the studies is mostly based on self-reports through questionnaires or interviews which is insufficient when differentiating between lumbar pain and PGP ${ }^{[8]}$. The condition is complex and underlying mechanisms remain unclear. However, pregnancy hormones soften and stretch the ligaments of the body allowing the pelvis to open slightly during labor thus allowing easier passage. This leads to a less stable pelvis. Some women appear to be capable to handle this increased range of motion by an improved muscle function whilst other women cannot ${ }^{[8]}$. Suggested risk factors are strenuous work ${ }^{[15]}$, previous history low back pain and/or previous PGP and previous trauma to the pelvis ${ }^{[8]}$. According to recent guidelines ${ }^{[8]}$ diagnosis can be reached only after exclusion of symptoms from the lumbar spine and should be based on the history and a standardized physical examination together with specific pelvic pain provocation tests.

PGP increases with advancing pregnancy and has a great impact on quality of life as it interferes with sleep, daily activities, work, motherhood and relationships ${ }^{[9,16-18]}$. Some women felt weakness of the legs and a typical sudden difficulty (locking) in moving one or the other leg forward. This symptom has been found to be specific for PGP and is known as "Catching of the leg" " ${ }^{[19]}$. PGP is a common cause of sick-leave, with reports suggesting that up to $72 \%$ of women take sick-leave because of their pain ${ }^{[20]}$. An increasing number of affected women request induction of labor or even elective caesarean section before the estimated date of birth in order to gain symptomatic relief ${ }^{[2]}$. Also, 85 to $95 \%$ of the women experienced a relapse during a subsequent pregnancy ${ }^{[2,20]}$ and fear of development of this pain can be reason to avoid new pregnancies ${ }^{[21]}$. Moreover, some women have stated that PGP was the beginning of a chronic condition ${ }^{[22]}$. These consequences make PGP a major public health issue. However it is often neglected due to the assumption that it is part of the normal aches and pains of pregnancy ${ }^{[2]}$.

Women experiencing these problems most often report them to their midwives. For example, in an Australian study, $71 \%$ reported their pain to their maternity caregiver ${ }^{[23]}$, but it appeared that few received much in the way of treatment. Pierce et al ${ }^{[23]}$ found that only $25 \%$ received any treatment whatsoever. Most women received information on how to self-manage PGP through postural changes, adaptations in lifting techniques, simple home exercises, rest, semi-plastic pelvic belts and pillows, massage and relaxation. Some women also received acupuncture and specific stabilizing exercises, which have been shown to reduce symptoms compared to standard treatment ${ }^{[9,24]}$. However, no data is available describing the proportion of women currently receiving treatment for PGP.

Research in this area has focused on prevalence and the evaluation of treatments of perceived pain, disability and health-related quality of life ${ }^{[9,24]}$. Qualitative studies are few. One study from Norway reported findings of a qualitative text analysis of internet discussions related to maternity health and back pain in pregnancy ${ }^{[25]}$. Another study from England described experiences of pain, disability and symphysispubis dysfunction in pregnant women ${ }^{[17]}$. However, this is a syndrome that complies to the sub-group symphysiolysis, which affects about $2 \%$ of women with PGP ${ }^{[13]}$. We have recently described that PGP made pregnant women question and doubt their roles and identities as mothers, partners and professionals ${ }^{[16]}$. These women had severe PGP according to pain intensity, health related quality of life (HRQL) scores and assessments by a specialized physiotherapist ${ }^{[26]}$. A recent study from Sweden presents findings from nine interviews of women with verified PGP performed from 2002 to $2004^{[18]}$. Their findings were similar to ours. However, studies describing experiences of severe pelvic girdle pain physically are lacking.

\section{Aim of the study}

This study explores and describes pregnant women's experiences of severe pelvic girdle pain physically and in regard to the healthcare care system. 


\section{Patients and methods}

A descriptive qualitative study was performed. The methodological approach in the study was qualitative with individual interviews and qualitative content analysis ${ }^{[27]}$ in an inductive way ${ }^{[28]}$. This method was chosen, as a qualitative method is applicable on different levels/depths of interpretation of a phenomenon. The aim is to provide a condensed and broad description of the phenomenon, and the outcome of the analysis are the concepts or categories describing the phenomenon ${ }^{[27]}$.

Informants were recruited from an ongoing randomised single-blind controlled trial ${ }^{[26]}$. Inclusion criteria in that study were healthy pregnant women with singleton fetuses at 12-29 completed gestational weeks, experiencing evening pain of more than or equal to $40 \mathrm{~mm}$ on a $100 \mathrm{~mm}$ visual analogue scale (VAS) during the baseline week. Participating women had to understand and read Swedish and have a diagnosis of PGP according to European guidelines ${ }^{[8]}$. This involved a history of pain between the posterior iliac crest and the gluteal folds, particularly in the vicinity of the sacroiliac joint along with or only in the symphysis pubis, a positive pain drawing with markings in the symphysis and/or in the gluteal areas distal and lateral to L5-S1, with or without radiating pain to the posterior thigh but not the foot, diminished endurance for standing, walking and sitting, free range of motion in the hips and spine, and no nerve root syndrome, i.e. exclusion of lumbar causes and a positive posterior pain provocation test ${ }^{[29]}$, and a and/or the symphysis pressure test ${ }^{[30]}$. The examination included Patrick's Faber test ${ }^{[30]}$, a modified Trendelenburg's test ${ }^{[30]}$, the Symphysis pressure test ${ }^{[30]}$ and the Posterior Pelvic Pain Provocation test (P4 test) ${ }^{[30]}$ and a functional test, the active straight leg test (ASLR) ${ }^{[31]}$. Women with other pain conditions, a history of orthopaedic disease or surgery of the spine or pelvic girdle or with systemic disorders were excluded. Outcomes in the RCT were pain, (visual analogue scale $0-100 \mathrm{~mm}$ ) ${ }^{[32]}$, with the anchor points, "no pain" and "worst considerable pain"), pain unpleasantness (VAS 0-100 mm, with the anchor pints "'no unpleasantness" and "worst considerable unpleasantness", function (Disability Rating Index) ${ }^{[33]}$, and Oswestery Disability Index ${ }^{[34]}$, HRQL (EuruQol-5D and EuroQol-VAS) ${ }^{[35]}$ and, severity of PGP according to a physical examination, including pain provocation tests ${ }^{[8]}$ and a functional test ${ }^{[36]}$. Only women that received craniosacral therapy (CST) were included in the qualitative study. CST is recommended for all musculoskeletal problems, especially back pain. This therapy is one type of complementary/alternative medicine; a form of gentle "hands on" treatment mainly applied to the head and neck area with claimed effects of released tension in the fascia, ligaments and muscles of the sacral region ${ }^{[37]}$.

Informants were selected through a purposive sampling. Recruitment was in two steps. First, 27/62 women receiving CST in the RCT were selected and contacted individually by phone by the first author (HE). If the woman was interested in participating in the qualitative study an invitation and a written explanation of the study was sent. About a week after the letter was received, the woman was again contacted to book an interview. None of the women declined participation. Informants in the study varied in age from 21-38 year old (mean = 31 years). One woman was high school educated, 12 had received college educations, and 14 had received university educations. Occupations varied from factory worker, gardener (two), nurse (three), preschool teacher (six), office clerk, professional (six,) designer, medical doctor, actress, and leader of clinical trials, waitress and physiotherapist. One woman was a student and one was unemployed. Swedish was not the first language for two women but none required an interpreter. All women were married/cohabiting. Six were expecting their first child, 16 their second, and five their third. Twenty women had experienced lumber-pelvic pain earlier and 15 women have had PGP in a former pregnancy. The results from the RCT showed that their PGP started early in pregnancy (mean 15 gestational weeks, SD 5.5). They had low HRQL scores (EuroQol-5D, median $=0.620$, EuroQol-VAS (median $50 \mathrm{~mm}$ ) ${ }^{[35]}$ and severe evening pain (VAS 0-100 mm, median $60.5 \mathrm{~mm}$ ). Participants were interviewed between May 2009 and June 2010. Interviews were conducted in conjunction with a CST (n=23) at the clinic or at the follow-up visit at the hospital $(n=2)$, at the university $(n=1)$ or in the woman's home $(n=1)$, depending on her preference. An in-depth interview technique ${ }^{[38]}$ was used to encourage informants to reflect and describe the women's experiences of PGP during pregnancy. An interview with an open-ended question was used: Can you tell me about your experiences of PGP during pregnancy? Follow-up questions were used. The interviewer created an open climate to enable the women to find the right words to express their lived experiences. Also, the interviews could help the women in the sense of giving them an opportunity to relate their experiences of PGP during pregnancy. If negative experiences were 
revealed in the interview, a follow-up meeting was offered. However, no such requests were made. The interviews were audio recorded and conducted by author HE. They lasted about 30 and 70 minutes (the majority lasting 60 minutes) and were transcribed verbatim.

Ethical approval was obtained from the regional ethics committee (ref: 703-09). Participating women were informed of the purpose and voluntary nature of the study and received both oral and written information. Women were assured of confidentiality and privacy, and the researcher guaranteed the data would be treated confidentially and that they were free to withdraw at any time without their treatment being affected. Women were enrolled after giving their written consent (WHO 2008).

The data was analysed using NVivo version 8 and did not start until all 27 individual interviews were completed. Two authors (HE and ER) independently analysed the data using conventional qualitative content analysis ${ }^{[27,39]}$. Content analysis involves identifying, coding and categorizing primary pattern emerging from the collected data ${ }^{[38]}$. At first, transcripts were read through repeatedly to obtain a composite perspective. Sentences or phrases that contained information were then selected. Lastly, a systematic analysis of interview responses was performed close to the context. Data from interviews was abstracted in subcategories and categories guided by the aim of the study ${ }^{[27,39]}$. To enhance trustworthiness, the analysis was critically discussed and compared among all authors, hence, moving back and forth between the entire text and subcategories and categories to enhance data credibility. Frequent discussions ensured thorough and consistent coding and led to the development of five categories after a thorough, comparative analysis ${ }^{[27]}$.

\section{Results}

The women's descriptions of severe pelvic girdle pain physically and in regard to the healthcare care system could be summarized in four categories (see Table 1) Selected quotations from the interviews are included to provide the reader with an opportunity to evaluate both the interpretations and credibility of the analysis ${ }^{[40]}$.

Table 1. Category system: Pregnant women's experiences of pelvic girdle pain as related to embodied experiences and experiences within the healthcare care system

\begin{tabular}{|c|c|}
\hline Sub-categories & Categories \\
\hline Unprepared for PGP & \\
\hline $\begin{array}{l}\text { Difficulties describing pelvic girdle pain } \\
\text { Experiencing PGP as the first sign of pregnancy } \\
\text { Not to recognize one's own body }\end{array}$ & A strange body \\
\hline $\begin{array}{l}\text { Inability to guide or control the body } \\
\text { Pain dominates existence } \\
\text { Uncertain of your own feelings }\end{array}$ & The body on guard \\
\hline $\begin{array}{l}\text { Knowledge of PGP in healthcare } \\
\text { To be acknowledged by the midwife }\end{array}$ & Relation and support from health care \\
\hline $\begin{array}{l}\text { Changed self-perception } \\
\text { Coping with PGP }\end{array}$ & Acceptance of PGP \\
\hline
\end{tabular}

\subsection{A strange body}

\section{Unprepared for PGP}

The women were disappointed by not having been informed of the existence of PGP. Women stressed that the first time they experienced PGP they lacked knowledge of what it was. It made them feel there was something seriously wrong and think that they were alone in experiencing the symptoms. 
You feel you're on your own. Why hasn't anyone told me when it's so common? You almost feel cheated. You want to cry out - tell me all about it! At least you will then be a little bit more prepared. Annie

\section{Difficulties describing pelvic girdle pain PGP}

Women stressed that it could be difficult describing PGP. Firstly, PGP was a diffuse feeling of discomfort, which gradually worsened. They described the pain as affecting all joints of the pelvis, and the pain often moved from one side to the other. Their bodies felt heavy, tired, stiff and tense as never before. The pain was sometimes muscular and occasionally similar to toothache. It could be a stabbing or cutting pain in the buttocks, or a dull pain in the back, which emerged from the groin, then moving to the hips and down the thighs. It gave burning sensations in the symphysis pubis, the genital area and labia.

It feels like someone is stabbing you in the back, and at the same time you feel as if you are going to be split in two ...you survive even if it hurts...It's like it's difficult to explain how and where it hurts and how it really feels. Kate

\section{Experiencing PGP as the first sign of pregnancy}

Women who experienced PGP for the second time said they were surprised that it could even be an early sign of pregnancy. It felt quite disturbing. Some women even experienced PGP before receiving the positive results of their pregnancy test. Only then were they sure they were again experiencing PGP during this new pregnancy. They had hoped not to be affected with PGP during this pregnancy since they had heard about other women who had remained pain-free. Many were disappointed. It felt discouraging, but at the same time, they knew that PGP would gradually disappear.

I was thinking - here we go again. Same old thing; it gives you 'flashbacks' and you can't, you just can't fall asleep. It's just not possible to avoid the pain. Lilly

\section{Not to recognize one's own body}

Women expressed that before becoming pregnant they took their bodies for granted. They were not used to aches and pains. Their bodies were like clockwork and never stopped them from completing tasks. One woman expressed that she was a novice as to how her own body functioned before getting pregnant. She stated, "It's only when you have gone through pregnancy and childbirth that you realize how your body works". The women pointed out that they no longer recognized their bodies, and found it hard to accept. It had changed, their entire body felt strange and different. Their bodies became a source of unpleasant sensations, which worried and frightened them. They were left to struggle with their bodies.

Stupid body, why are you treating me like this. Annie

\subsection{The body on guard}

\section{I nability to guide or control the body}

The women said that PGP prevented them from guiding and controlling their bodies. Women described how frustrating it was, to not be able to move about as they wanted. It felt as if they had a limited number of steps; that walking induced pain, and they had to pay for it in the days that followed.

Things work, until I move around more than I should, only if it's a matter of a few yards the pain then hits me with a vengeance. Sarah

Women spoke of how they missed the ability to be physically active. One woman said: I feel happier then, a bit more positive. The women also said that they were used to exercising to ease their back pain and that they were frustrated by the fact that their normal strategies in dealing with their back pain no longer worked. They were also anxious about not being able to move and change positions during the approaching delivery. 


\section{Pain dominates existence}

Some women described "a sudden sensation of immobility". Their legs felt like cement and it was impossible to move at all. This immobility gave them the feeling of being paralyzed. During the night, they didn't even dare to walk to the bathroom, but crawled instead. Some women suffered this immobility for a short while, others for a couple of hours, and some up to twelve hours before the sensation past. The fear of triggering this sensation again made them avoid movement.

Not only did it hurt but I also froze, feeling very stiff. I was paralyzed. That's when the fear crept in. Marilyn

Women pointed out that PGP disturbed their ability to sleep and left their bodies feeling fatigued. Every time they changed position, they woke up because of the pain. What made it even more complicated was all the pillows they had to have with them in order to get comfortable. Women pointed out that they didn't get the necessary sleep to recover and feel rested.

Your body feels exhausted, a feeling of tiredness that you can't get rid of. Resting doesn't help. Your back and your body feels, like, tired. It's difficult to get moving again. Susan

\section{Uncertain of your ow $\mathrm{n}$ feelings}

Women explained how PGP affected them, constantly. They felt worn out, frustrated, moody, close to tears and quick to complain. They knew they were taking out these feelings on their families. Being unhappy and discontent made them feel guilty. They couldn't feel the euphoria they felt they were supposed to feel. They said they were feeling tense, exhausted and without energy. Their minds were constantly shifting, and they were struggling to hold out. Some women even thought they were suffering from depression.

It affects your psyche, to be in constant pain, as you do. Sometimes more, sometimes less. You lack the patience you're used to having. Rose

Some reflected on the fact that the consequences of PGP affected enjoyment of their pregnancy and unborn child. Some women stressed how they wanted to know the sex of the unborn baby. They felt this would help them bond with their unborn babies.

I was not in top form at all. My mood was low and I felt depressed. To start with, I had great difficulties bonding with my child. Linda.

\subsection{Relation and support from health care}

\section{Knowledge of PGP in healthcare}

Women, who hadn't previously experienced PGP, explained how they had called the Social Insurance Agency (SIA) to enquire about what they were suffering from. Some were told they were suffering from back pain. Others were told they had a deep-seated blood clot that needed urgent attention. Some women felt that when they made an appointment with their GP they were met by lack of knowledge and understanding. They received little support and much criticism. This led them to feeling misunderstood and insulted. One woman said she was made to feel that she only had herself to blame for becoming pregnant.

My doctor, he told me that his wife had suffered from PGP, so he knew all about it. No worries, this made me sad. So once again I have to return to this pain. Jill

Women really appreciated doctors with knowledge of PGP and didn't treat the problem lightly. They felt most reassured when given a thorough examination, relevant information, and credibility. 
Finally I got to meet this wonderful doctor who knew exactly what she was talking about. She performed all these tests. It really hurt, but wow, she knew exactly where to press to trigger the pain...and then she wrote it down, in that medical gibberish, where it hurt. Then I felt really, really happy. Liza

\section{To be acknowledged by the midwife}

The women expressed feeling safe and well taken care of if they had a good relationship with their midwife. However, some women pointed out that they had to suffer longer than necessary due to few visits to the midwife early in pregnancy. Nevertheless, they greatly appreciated the information provided, for example where to get an elastic pelvic belt and how to get in touch with a physiotherapist. However, some women experienced poor care from their midwives, where they had to take initiative themselves and actively seek support. They felt their midwives offered no help. They had to find the necessary information on their own, which was sometimes difficult depending on how badly they felt. The women said that they felt a brochure would have been useful. A woman said that if she had got one, she would have at least known she wasn't alone in experiencing PGP.

The midwife had too little information. I think the doctor's part in the overall treatment was to persuade the SIA that I wasn't fit for work. Lilly

\section{Attitudes and acceptance of sick leave in health care}

The women explained how they failed to use their right to sick leave, while others avoided sick leave for as long as possible. They appreciated the doctors' decision to put them on part-time sick leave when full-time work was no longer possible.

I tried to go back for two days, but was completely shattered. I then told the doctor that I didn't know if the SIA would show consideration. The doctor said they probably wouldn't, but I certainly will. If you work part-time, you will probably manage to work during the rest of your pregnancy. Liza

Women reported how they worried about the SIA not approving sick leave. Their main concern was a certificate from the physician. It had to be formulated in such a way that the SIA wouldn't question it. A dispute with the SIA could affect them negatively and perhaps lead to increased PGP.

I was worried that the SIA would cause me a lot of problems, but they've been fine. At the same time I was thinking that as long as I don't have to work we will manage our economic situation. Sophie

\subsection{Acceptance of PGP}

\section{Coping with PGP}

It was just realizing that they had to be aware and accept their bodies' limitations and work with their bodies and not against them. It meant resisting activities that worsened their pain and drained them of energy. They emphasized maintaining a slower pace, to be more caring toward their bodies. PGP made them aware of their bodies' inabilities and realize that there was no point in feeling sorry for them. One woman said:

The more you fight it, the worse the PGP. If you try to ignore it, the pain just increases. But if you just accept the situation you start to feel a lot better. Alice

Sometimes they choose the opposite that was recommended, which they knew should increase their pain.

Sometimes I can handle it but I get pain afterwards. Still, it's my own choice....but constant pain demands a lot of planning and energy. Lilly 


\section{Changed self-perception}

The women stressed that PGP had made them take life more seriously and that their self-perception had changed. One woman said that before PGP she thought she was Supergirl.

To start with, I think I was a bit pigheaded. However, as soon as I had some understanding, I could adjust to the new situation. I know that PGP is not dangerous...but constant pain demands a lot of planning and energy. Lilly

\section{Discussion}

The women's descriptions of experiences of PGP as related to embodied experiences and experiences within the healthcare care system are: a strange body; the body on guard; relation and support from health care and acceptance of PGP.

The women expressed that their PGP had resulted in a strange body and a source of unpleasant sensations, which worried and frightened them. They were frustrated by the fact that their normal strategies e.g. exercising to ease their back pain no longer worked. Some women even thought they were suffering from depression. It is important to take these feelings seriously since depression is associated with PGP ${ }^{[41]}$. The women expressed that they were unable to guide or control their bodies due to PGP and how frustrating this was. Inability to move made them anxious about not being able to move and change positions during the approaching delivery. It has been described that women affected with PGP typically adopt abnormal patterns of muscle activity, to relieve and avoid pain. The longer this pattern persists, the more pain will arise from the unphysiological burden on muscles and joints, and the pain in turn will aggravate dysfunction of muscles resulting in a vicious cycle ${ }^{[8]}$. The sensation, described by the women as "a sudden sensation of immobility" or feelings of being paralyzed, was so unpleasant that it made them avoid movement and has been defined as 'catching of the leg'. This sensation is described solely in patients with PGP, not in patients with ordinary low back pain ${ }^{[19]}$. The most probable explanation for 'the catching' is that local nociception disturbs muscular function in women with PGP because changes in the sacroiliac joint's range of motion, which is very small, cannot cause this symptom ${ }^{[19]}$. It seems important that women with PGP are provided information about this sensation to reduce their fear. The women described that pain dominated their entire existence. They told of how their moods were constantly shifting, and how they struggled to carry on. It is known that anxiety about impending pain in itself can trigger activation of hormones, for example cholecystokinin which, in turn, facilitates pain transmission and leads to a real worsening of pain ${ }^{[42]}$. Also, $74 \%$ of the women had recurrent pain in pregnancy and therefore perhaps some of their perceptions may also reflect cumulative experience. Pain is defined by the International Association for the Study of Pain (IASP) ${ }^{[43]}$, as an unpleasant sensory and emotional experience associated with actual or potential tissue damage or described with such damage. However, pain is also described as a perceptual experience that involves emotional, physiological, cognitive, environmental and social factors ${ }^{[44]}$. Thus, it is possible that the multitude of cognitive and psychological stressors may have contributed to the development of PGP. It is also well known that pregnancy is often associated with increased sensitivity, emotional lability and anxiety ${ }^{[45]}$. However, that PGP can cause women to worry about not being able to bond with their unborn child has not been reported earlier. But there were few women that expressed this spontaneously and results from a small sample of informants cannot be generalized. However it is an important finding, and these fears and doubts can be shameful and also present in other (difficult) life situations during pregnancy. This need to be further explored and acknowledged among healthcare personnel so that they can provide these women with the necessary support.

The women sought support from health care professionals and emphasized the importance of relationships with professionals to be based on trust, confidence, familiarity, mutual respect, shared decision making, and good communication. The women spoke of low standards in healthcare and insufficient knowledge among health care workers. They had to take the initiative and ask for information about PGP, support and care. Some women stressed how they felt mistrusted and that their pain was trivialized. They were worried that sick leave prescribed by their physicians would not be approved. These feelings increased their worry and may have increased their pain, as it is known that emotions such as 
anxiety, anger, worry or frustration can affect perception of pain ${ }^{[46]}$. A lack of acknowledgement or support from health care professionals who tended to define PGP as normal, thus questioning the women's experiences, is consistent with the two earlier studies ${ }^{[17,25]}$, but also with experiences, of pregnant women with other disabling conditions ${ }^{[47,48]}$. However, some women in our study described being well taken care of by midwives and doctors. They felt their concern and bodily experiences were taken seriously and expressed how important this was to them. Positive support e.g. proper care, attention, and adequate information that lead to positive expectations can effect neurochemical systems, i.e. endogenous opioids, and lead to a placebo-elicited inhibition of pain ${ }^{[49]}$. Also, patients have the right to care based upon sound, scientifically proven and updated knowledge and practice, delivered by competent practitioners to meet their needs ${ }^{\text {[50] }}$.

The strengths of the study include the fact that interviews were all conducted, transcribed and analysed by the same person, which is considered important in qualitative research ${ }^{[39]}$. In addition, the qualitative design enabled assessment of the experiences of PGP in more detail and depth compared to a quantitative approach using questionnaires ${ }^{[51]}$. The purposive sampling helped us to achieve a broad sample including women from diverse socioeconomic backgrounds who varied in age, education, and prior experience of PGP. However, this study had several limitations. As in all qualitative studies it must be related to its context ${ }^{[39]}$. This study included women who participated in an RCT. All had received additional information and treatment for PGP, which may have affected their perceptions of PGP. They were all married/cohabitating and lived in stable social situations. However, the fact that the findings are contextual does not mean that they lack meaning in other contexts. They must, however, be transferred and interpreted in relation to other contexts. Therefore, the extent of transferability of the results of this qualitative study to other settings and populations depends on cultural and traditional similarities or differences, and should be done with caution. One of the authors (HE) has long experience of helping and treating women with PGP during pregnancy and the postpartum period. Pre-understanding based on long experience may have a negative influence when gathering data and carrying out analyses in qualitative research. However, researchers were aware of this early on, and constant commitment by the co-authors without this experience counterbalanced this pre-understanding, enabling exploration and discussion of the data in a balanced manner.

\section{Conclusion}

PGP completely preoccupied women with severe PGP. It influenced their self-evident trust in their bodies as well as their capabilities to guide and control them. The fear of triggering pain and unpleasant sensations made them avoid movement. They experienced anxiety and worry of not being able to manage their pregnancy and childbirth, and bind to their unborn child. They felt worse that their complaints are trivialized, and not taken seriously in health care. To be able to cope with PGP, they had to accept it and realize that they have to be aware and accept their bodies' limitations. This means working with their bodies and not against them. PGP made the women look upon life more seriously and changed their self-perception. This study provides an increased awareness and knowledge of PGP during pregnancy. The effect of its symptoms and knowledge of the possible influence on the body-mind, and the ability to function in daily life and work are needed among healthcare personnel and authorities to enable them to meet the women's needs and provide them with adequate support. Since PGP is such a common condition during pregnancy a brochure about PGP, (its frequency, symptoms, and relief) along with information on whom they can turn to in the event of PGP, could be sent home with the woman at the first visit to the midwife. This would probably prevent or reduce the worry that can arise in women suffering PGP. More research is needed on this widespread problem of pregnancy. Additional studies need to be performed to determine mechanisms and prevention of PGP and effective treatment modalities. It is also of interest to examine how the women's men experience the period of PGP and how they cope with it.

\section{Acknowledgement}

We want to express our appreciation to all the women for their contributions to this study. We thank language editor Mark Rosenfeld who made significant revisions to the manuscript. 


\section{Source(s) of support}

This study was supported by research grants from The Health \& Medical Care Committee of the Regional Executive Board, Region Vastra Götaland (Sweden), grant number: VGFOUREG-155171.

\section{Contributors}

All authors participated in the design and interpretation of the results and drafting of the article. HE contributed to recruitment procedures, data collection, data analysis and management of the trial. IL and ERO contributed to analysis of the data.

\section{References}

[1] Wu WH, Meijer OG, Uegaki K, Mens JM, van Dieën JH, Wuisman PI, Ostgaard HC. Pregnancy-related pelvic girdle pain (PPP), I: Terminology, clinical presentation, and prevalence. Eur Spine J. 2004 Nov; 13(7): 575-589. Epub 2004 Aug 27. http://dx.doi.org/10.1007/s00586-003-0615-y

[2] Vermani E, Mittal R, Weeks A. Pelvic girdle pain and low back pain in pregnancy: a review. Pain Pract. 2010 Jan-Feb; 10(1): 60-71. http://dx.doi.org/10.1111/j.1533-2500.2009.00327.x

[3] Bjorklund K, Bergstrom S. Is pelvic pain in pregnancy a welfare complaint? Acta Obstet Gynecol Scand. 2000 ; 79: 24-30. http://dx.doi.org/10.1080/j.1600-0412.2000.079001024.x

[4] Jones C, Cameron M. Pelvic girdle pain during pregnancy and puerperium. J Obstet Gynaecol. 2012 Aug; 32 (6): 607. http://dx.doi.org/10.3109/01443615.2012.685904

[5] Kanakaris NK, Roberts CS, Giannoudis PV. Pregnancy-related pelvic girdle pain: an update. BMC medicine. 2011; 9(1): 15. http://dx.doi.org/10.1186/1741-7015-9-15

[6] Mousavi SJ, Parnianpour M, Vleeming A. Pregnancy related pelvic girdle pain and low back pain in an Iranian population. Spine (Phila Pa 1976). 2007 Feb 1; 32(3): E100-104.

[7] Mukkannavar P, Desai BR, Mohanty U, Kulkarni S, Parvatikar V, Daiwajna S.Pelvic girdle pain in Indian postpartum women: a cross-sectional study. Physiother Theory Pract. 2014 Feb; 30(2): 123-130. http://dx.doi.org/10.3109/09593985.2013.816399

[8] Vleeming A, Albert HB, Ostgaard HC, Sturesson B, Stuge B. European guidelines for the diagnosis and treatment of pelvic girdle pain. Eur Spine J. 2008 Jun; 17(6): 794-819. http://dx.doi.org/10.1007/s00586-008-0602-4

[9] Pennick V, Liddle SD. Interventions for preventing and treating pelvic and back pain in pregnancy. Cochrane Database Syst Rev. 2013 Aug 1; 8: CD001139.

[10] Robinson HS, Mengshoel AM, Bjelland EK et al. Pelvic girdle pain, clinical tests and disability in late pregnancy. Manual therapy 2010; 15: 280-285. http://dx.doi.org/10.1016/j.math.2010.01.006

[11] Mogren IM, Pohjanen AI. Low back pain and pelvic pain during pregnancy: prevalence and risk factors. Spine (Phila Pa 1976). 2005 Apr 15; 30(8): 983-891.

[12] Elden H, Hagberg H, Olsen MF, Ladfors L, Ostgaard HC. Regression of pelvic girdle pain after delivery: follow-up of a randomised single blind controlled trial with different treatment modalities. Acta Obstet Gynecol Scand. 2008; 87(2): 201-208. http://dx.doi.org/10.1080/00016340701823959

[13] Albert H, Godskesen M, Westergaard J. Prognosis in four syndromes of pregnancy-related pelvic pain. Acta Obstet Gynecol Scand. 2001 Jun; 80(6): 505-510. http://dx.doi.org/10.1080/j.1600-0412.2001.080006505.x

[14] Röst CC, Jacqueline J, Kaiser A, Verhagen AP, Koes BW. Prognosis of women with pelvic pain during pregnancy: a long-term follow-up study. Acta Obstet Gynecol Scand. 2006; 85(7): 77. http://dx.doi.org/10.1080/00016340600626982

[15] Juhl M, Andersen PK, Olsen J, Andersen AM. Psychosocial and physical work environment and risk of pelvic pain in pregnancy. A study within the Danish national birth cohort. J Epidemiol Community Health. 2005 Jul; 59(7): 580-585. http://dx.doi.org/10.1136/jech.2004.029520

[16] Elden H, Lundgren I, Robertson E. Life’s pregnant pause of pain: Pregnant women's experiences of pelvic girdle pain related to daily life: A Swedish interview study. Sex Reprod Healthc. 2013 Mar; 4(1): 29-34. http://dx.doi.org/10.1016/j.srhc.2012.11.003

[17] Wellock K, Crichton M. Pain, disability and symphysis pubis dysfunction: women talking. Evidence Based Midwifery. 2008 (2008); 6: 9-17.

[18] Persson M, Winkvist A, Dahlgren L, Mogren I. "Struggling with daily life and enduring pain": a qualitative study of the experiences of pregnant women living with pelvic girdle pain. BMC Pregnancy Childbirth. 2013 May 13;13:111. http://dx.doi.org/10.1186/1471-2393-13-111 
[19] Sturesson B, Uden G, Uden A. Pain pattern in pregnancy and "catching" of the leg in pregnant women with posterior pelvic pain. Spine (Phila Pa 1976). 1997 Aug 15; 22(16): 1880-1883; discussion 1884.

[20] Mogren I. Perceived health, sick leave, psychosocial situation, and sexual life in women with low-back pain and pelvic pain during pregnancy. Acta Obstet Gynecol Scand. 2006; 85(6): 647-656. http://dx.doi.org/10.1080/00016340600607297

[21] Padua L, Padua R, Bondi R et al. Patient-oriented assessment of back pain in pregnancy. Eur Spine J. 2002 Jun;11(3):272-275. http://dx.doi.org/10.1007/s00586-002-0391-0

[22] Svensson HO, Andersson GB, Hagstad A, Janson PO. The relationship of low-back pain to pregnancy and gynecologic factors. Spine (Phila Pa 1976). 1990 May; 15(5): 371-375.

[23] Pierce H, Homer CS, Dahlen HG, King J. Pregnancy-related lumbopelvic pain: listening to Australian women. Nurs Res Pract. 2012(2012); 387428. http://dx.doi.org/10.1155/2012/387428

[24] Elden H, Ladfors L, Olsen MF, Ostgaard HC, Hagberg H Effects of acupuncture and stabilising exercises as adjunct to standard treatment in pregnant women with pelvic girdle pain: randomised single blind controlled trial. BMJ. 2005 Apr 2; 330(7494): 761-764. Epub 2005 Mar 18. http://dx.doi.org/10.1136/bmj.38397.507014.E0

[25] Haukeland-Fredriksen E, Moland K, Sundby J. Listen to your body. A qualitative text analysis of internet discussions related to pregnancy health and pelvic girdle pain in pregnancy. Patient Education and Counseling. 2008; 73(2): 294-299

[26] Elden H, Östgaard HC, Glantz A, Marciniak P, Linnér AC, Olsén MF. Effects of craniosacral therapy as adjunct to standard treatment for pelvic girdle pain in pregnant women: a multicenter, single blind, randomized controlled trial. Acta Obstet Gynecol Scand. 2013 Jul; 92(7):775-782. http://dx.doi.org/10.1111/aogs.12096

[27] Hsieh H, Shannon S. Three approaches to qualitative content analysis. Qualitative health research 2005; 15: $1277-1288$. http://dx.doi.org/10.1177/1049732305276687

[28] Elo S, Kyngas H. The qualitative content analysis process. J Adv Nurs. 2008 Apr; 62(1): 107-15. http://dx.doi.org/10.1111/j.1365-2648.2007.04569.x

[29] Ostgaard HC, Zetherstrom G, Roos-Hansson E. The posterior pelvic pain provocation test in pregnant women. Eur Spine J. 1994;3(5):258-260. http://dx.doi.org/10.1007/BF02226575

[30] Albert H, Godskesen M, Westergaard J. Evaluation of clinical tests used in classification procedures in pregnancy-related pelvic joint pain. Eur Spine J. 2000 Apr; 9(2): 161-166. http://dx.doi.org/10.1007/s005860050228

[31] Mens JM, Vleeming A, Snijders CJ, Ginai AC, Stam HJ. Responsiveness of outcome measurements in rehabilitation of patients with posterior pelvic pain since pregnancy. Spine (Phila Pa 1976). 2002 May 15; 27(10): 1110-1115.

[32] Huskinsson E. Measurement of pain. J Rheumatol. 1982 Sep-Oct; 9(5): 768-769.

[33] Sahlen B, Sprangfort E, Nygren Å. Nordemar R. The Disability Raiting Index: an instrument for the assessment of disability in clinical settings J Clin Epidemiol. 1994 Dec; 47(12): 1423-1435. http://dx.doi.org/10.1016/0895-4356(94)90086-8

[34] Ferreira P. Specific stabilising exercise improves pain and function in women with pelvic girdle pain following pregnancy. Aust $\mathrm{J}$ Physiother. 2004; 50(4): 259.

[35] Rabin R, de Charro F. EQ-5D: a measure of health status from the EuroQol Group. Ann Med. 2001 Jul;33(5):337-343. http://dx.doi.org/10.3109/07853890109002087

[36] Mens JM, Vleeming A, Snijders CJ, Koes BW, Stam HJ.Validity of the active straight leg raise test for measuring disease severity in patients with posterior pelvic pain after pregnancy. Spine (Phila Pa 1976). 2002 Jan 15;27(2):196-200.

[37] Jakel A, von Hauenschild P. A systematic review to evaluate the clinical benefits of craniosacral therapy. Complement Ther Med. 2012; 20(6): 456-465. http://dx.doi.org/10.1016/j.ctim.2012.07.009

[38] Polit D, Beck C. Nursing Research, Generating and Assessing Evidence for Nursing Practice China: Wolters Kluwer/Lippincott Williams\&Wilkins; 2008.

[39] Graneheim U, Lundman B. Qualitative content analysis in nursing research: Concepts, procedures and measures to achieve trustworthiness. Nurse Educ Today. 2004 Feb;24(2):105-112. http://dx.doi.org/10.1016/j.nedt.2003.10.001

[40] Dahlberg K, Dahlberg H, Nyström M. Reflective life world research Lund: Studentlitteratur; 2008.

[41] Kovacs FM, Garcia E, Royuela A, González L, Abraira V; Spanish Back Pain Research Network. Prevalence and factors associated with low back pain and pelvic girdle pain during pregnancy: a multicenter study conducted in the Spanish National Health Service. Spine (Phila Pa 1976). 2012 Aug 1;37(17):1516-1533.

[42] Colloca L, Benedetti F. Nocebo hyperalgesia: how anxiety is turned into pain. Curr Opin Anaesthesiol. 2007 Oct; 20 (5): $435-439$. http://dx.doi.org/10.1097/ACO.0b013e3282b972fb

[43] Pain terms: a list with definitions and notes on usage. Recommended by the IASP Subcommittee on Taxonomy. Pain. 1979 Jun;6(3):249.

[44] Holdcroft A, Power I. Recent developments: management of pain. BMJ. 2003 Mar 22;326(7390):635-639. 
http://dx.doi.org/10.1136/bmj.326.7390.635

[45] Light HK, Fenster C. Maternal concerns during pregnancy. Am J Obstet Gynecol. 1974 Jan 1;118(1):46-50.

[46] Wiech K, Tracey I. The influence of negative emotions on pain: behavioral effects and neural mechanisms. Neuroimage. 2009 Sep; 47(3): 987-994. http://dx.doi.org/10.1016/j.neuroimage.2009.05.059

[47] Payne D, McPherson K. Becoming mothers: Multiple sclerosis and motherhood: A qualitative study. Disabil Rehabil. 2010;32(8):629-638. http://dx.doi.org/10.3109/09638280903204708

[48] Nolan J, McCrone S, Azulay Chertok I. The maternal experience of having diabetes in pregnancy. J Am Acad Nurse Pract. 2011 Nov;23(11):611-618. http://dx.doi.org/10.1111/j.1745-7599.2011.00646.x

[49] Petrovic P, Kalso E, Petersson KM, Andersson J, Fransson P, Ingvar M. A prefrontal non-opioid mechanism in placebo analgesia. Pain, 150(1), 59-65. Pain. 2010 Jul; 150(1): 59-65. http://dx.doi.org/10.1016/j.pain.2010.03.011

[50] Hunter S. Determination of moral negligence in the context of the undermedication of pain by nurses. Nurs Ethics. 2000 Sep; 7(5): 379-391.

[51] Grbich C. Qualitative data analysis London: Sage; 2007. 